\title{
Failure Analysis of Tube Radiant Heater Hot Oil in Refinery Industry
}

\author{
Moch Ardi Dimastiar ${ }^{1,2, *}$, Ahmad Taufik², and Anne Zulfia Syahrial ${ }^{1}$ \\ ${ }^{1}$ Department Metallurgy and Materials, Faculty of Engineering, University of Indonesia, Depok, Indonesia \\ ${ }^{2}$ AT Solusi Ltd., Jakarta, Indonesia
}

\begin{abstract}
Heater, known as a furnace or fired heater is used to heat the oil which flows through tubes around a flame. When the tubes are failed, the fired heater reliability is affected. This paper investigates the probable cause/ causes of the radiant tube failure in the fired heater. In that context, depth analysis is conducted as part of the investigative studies, involve visual observation and dimensional measurement, metallographic examination, and chemical analysis. Finally, it has been concluded that the tube radiant has mainly failed due to crevice corrosion. In the other side, spherodization and external corrosion are also found as other failure contributors.
\end{abstract}

\section{Introduction}

A fired heater (Fig. 1) is a direct-fired heat exchanger which uses the hot gases of combustion to raise the temperature of a fluid flowing through tubes. Heat is transferred to the fluid by both mechanisms of heat transfer, radiation and convection. The fluid is first heated in the convection section preheat coil which is followed by further heating in the radiant section [1]. Generally, tubes are designed with carbon steel.

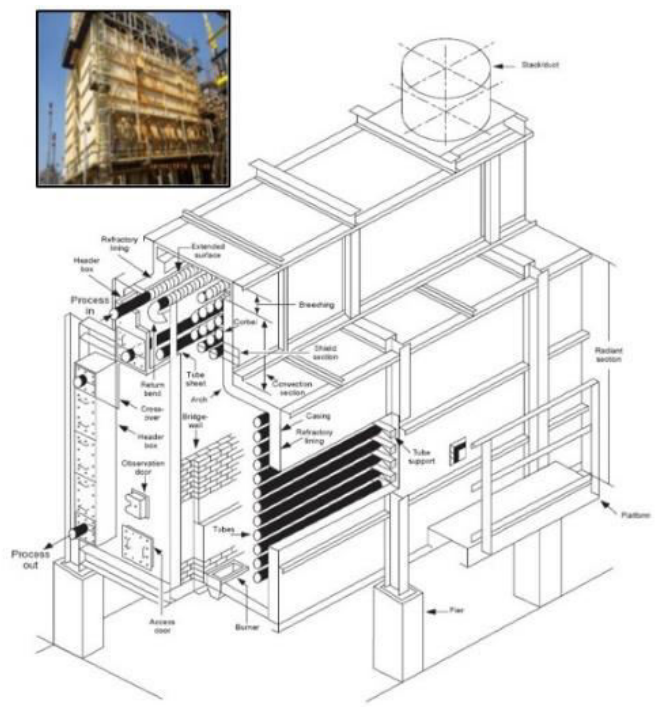

Fig. 1. Fired heater

The failure of fired heater component is one of the cause for the unscheduled outage. Different damage mechanism such as corrosion, creep, and erosion, are responsible for the component failure. In spite of the best effort of design engineers and material scientists, engineering components are subject to failure during operation. In some cases, failure may lead to affect the reliability, availability and safety of the equipment. This finally leads to huge financial loss, therefore, it is essential to investigate the failure root cause in the fired heater. The root cause of failure has been conducted to prevent the repetitive failure in near future and at the same time, remedial measures are also highlighted to avoid similar failure [2].

In this paper, an effort has been made to investigate the probable cause/ causes of tube radiant failure. The thing which makes this analysis interesting is that the similar case of failure has occurred several years ago with the same failure mode, location, and also position of the failure. The location and appearance of failure in the fired heater are shown in Fig. 2 and Fig. 3, respectively.

\footnotetext{
Corresponding author: ardi.dimastiar@gmail.com
} 


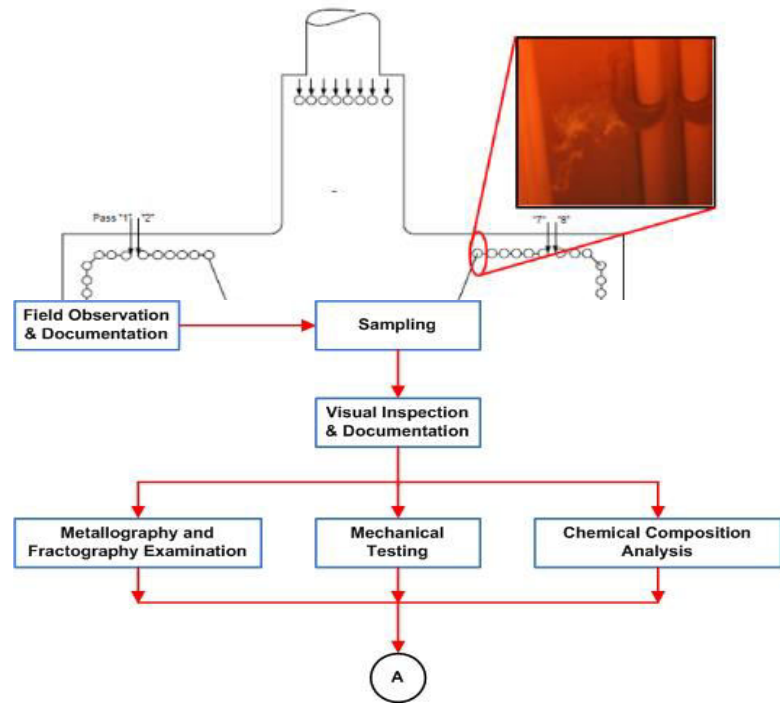

Fig. 2. Location of failure in the radiant tube of the fired heater (pass $7^{\text {th }}$, number $6^{\text {th }}$ )

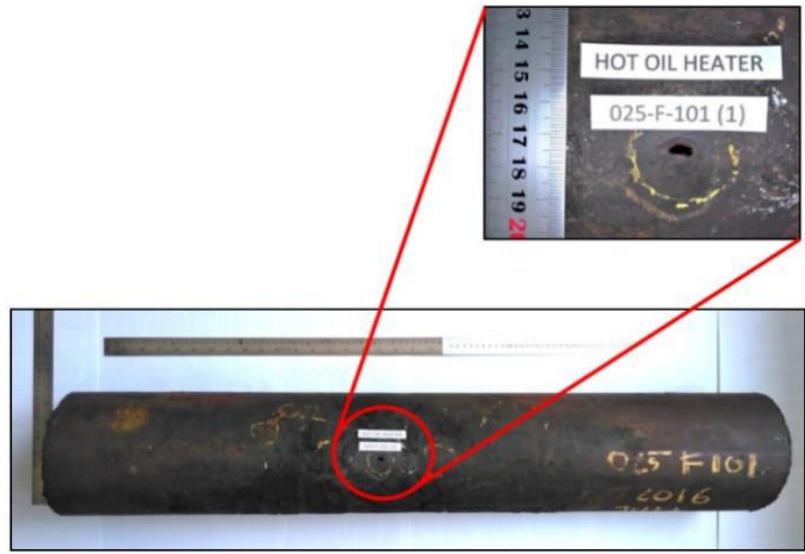

Fig. 3. Failure image of leakage (outside view)

The material specification, design and operating parameters of the tube failure as obtained from the plant are given as follows.

1. Material specification of the tube: A-106 Gr. B.

2. Working temperature and pressure of the tube $(\max ): 310^{\circ} \mathrm{C}\left[590^{\circ} \mathrm{F}\right]$ and $6.1 \mathrm{~kg} / \mathrm{cm}^{2}$.

3. Location of failure: pass $7^{\text {th }}$, number $6^{\text {th }}$; around six o'clock, close to the support/ hanger.

4. Effective running hours: $96,000 \mathrm{~h}$ (approx).

5. Nominal pipe size and the wall thickness of the tube: 6 inches (outside diameter $=6.625$ ) $\mathrm{x}$ Schedule 40 (wall thickness $=0.28$ inch).

The material will be analyzed in depth which involves: 1) Visual observation and dimensional measurement, 2) Metallographic examination, and 3) Chemical analysis.

\section{Methodology}

Flow diagram of failure analysis as shown in Fig. 4 involves systematic and comprehensive analysis to determine the root cause of the failure [3-4]. The root cause of the failure is determined by the result of test series which is conducted at the laboratory as well as the results of literature study.

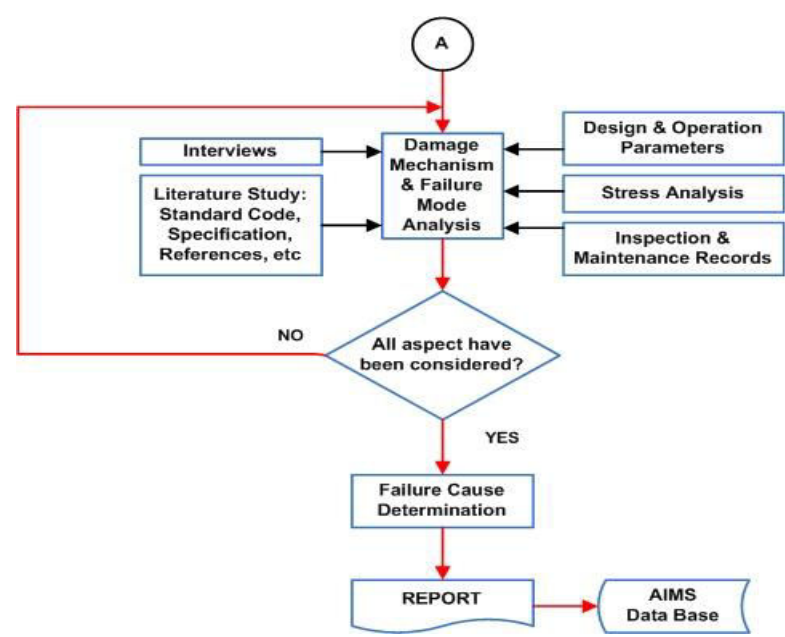

Fig. 4. Failure analysis methodology

\section{Test and Result}

\subsection{Visual Observation and Dimensional Measurement}

Visual observation shows that the failure of the tube was leakage (Fig. 5). The figure also shows the deposited around the failure zone.
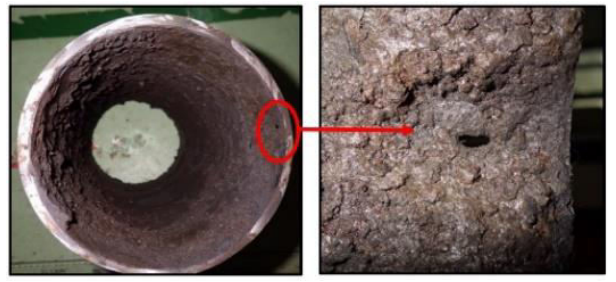

Fig. 5. Failure image (inside view)

The outer diameter (OD) was measured manually using a ruler and the result was found comply with the specification. Wall thickness of the cross-sectional area was also measured using digital vernier calliper and the thickness found to be different at some location (Fig. 6).

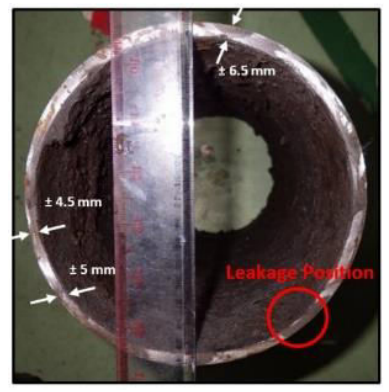

Fig. 6. Outside diameter and wall thickness measurement

Then, further wall thickness measurement was conducted at three different positions (top, bottom/ 
failure location, and right), along with the tube surface (about $420 \mathrm{~mm}$ length), and found the erosion phenomena at bottom of the tube, $1^{\text {st }}$ measurement position and direction (Table 1).

Table 1. Wall thickness measurement result along the tube surface

\begin{tabular}{|c|c|c|c|c|}
\hline $\begin{array}{c}\text { Measurement Position and } \\
\text { Direction }\end{array}$ & $\begin{array}{c}\text { The result of Wall Thickness } \\
\text { Measurement }\end{array}$ \\
\hline \multirow{3}{*}{} & Point & $\mathbf{1}$ & $\mathbf{2}$ & $\mathbf{3}$ \\
\cline { 2 - 5 } & 1 & 6.08 & 6.47 & 6.64 \\
\cline { 2 - 5 } & 2 & 6.2 & 6.27 & 6.7 \\
\cline { 2 - 5 } & 3 & 6.57 & 6.75 & 6.64 \\
\cline { 2 - 5 } & 4 & 6.14 & 6.34 & 6.81 \\
\hline & 5 & 6.32 & 6.54 & 6.69 \\
\hline & 6 & 6.40 & 6.43 & 6.56 \\
\hline & 7 & 6.38 & 6.89 & 6.62 \\
\hline & 8 & 6.05 & 6.54 & 6.64 \\
\hline & 9 & 5.96 & 6.45 & 6.71 \\
\hline & Ave. & $\mathbf{6 . 2 3}$ & $\mathbf{6 . 5 2}$ & $\mathbf{6 . 7 1}$ \\
\hline
\end{tabular}

\subsection{Metallographic Examination}

The samples representation were cut at the tube surface, near failure region as well as away from the failure region for microstructural analysis. The samples were cut and mounted for metallographic examination. All the samples are mirror polished up to $1 \mu \mathrm{m}$, then etched with $2 \%$ nital. Both of the samples show ferrite-pearlite microstructure (Fig. 7).
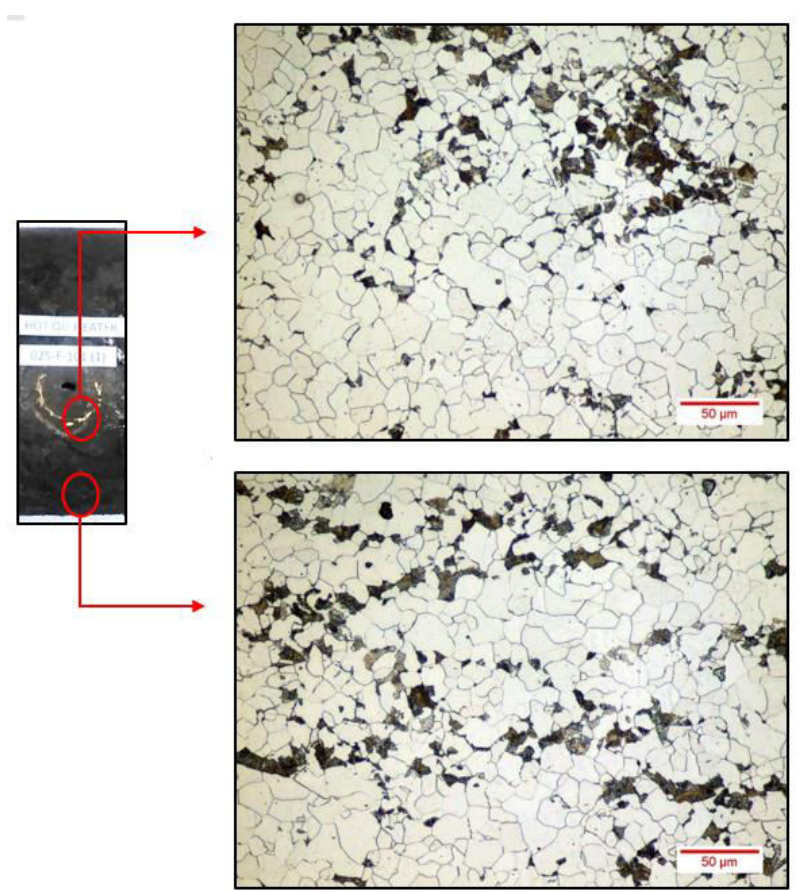

Fig. 7. The microstructure of failure tube, taken from the surface, close to and away from the leakage showing the ferrite-pearlite microstructure

The other samples were cut from the failure region and prepared with the same method as previous. The microstructure at the failure region at etched conditions showed initial signs of carbide spheroidization (Fig. 8, $1 \mathrm{~A}$ and 2A).

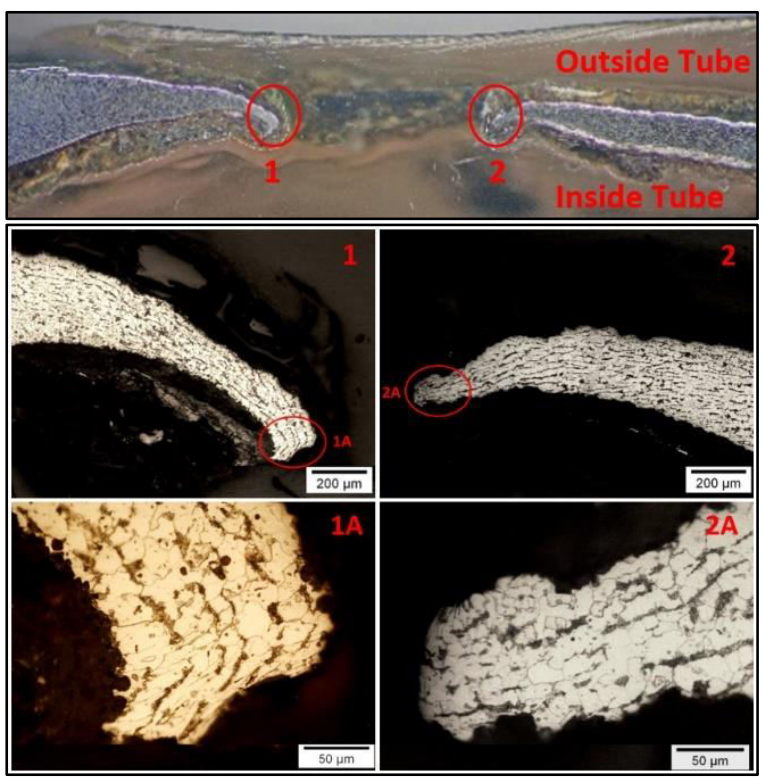

Fig. 8. The microstructure of failure region (cross-sectional area) showing the initial signs of carbide spheroidization, usually accompanied by precipitation at grain boundaries

Further analyses were conducted using scanning electron microscope at the surface of internal (Fig. 9) and an external tube of samples (Fig. 10). The result showed the corrosion scale/ deposited which are spreaded around the grain and boundary. 


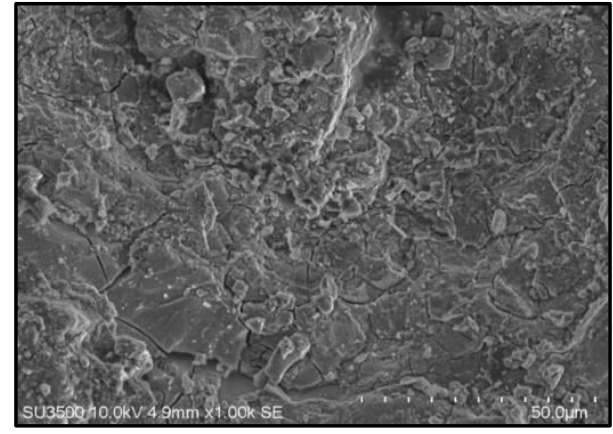

Fig. 9. SEM image, taken from the internal surface of failure tube, showing the corrosion scale/ deposited which are spreaded around

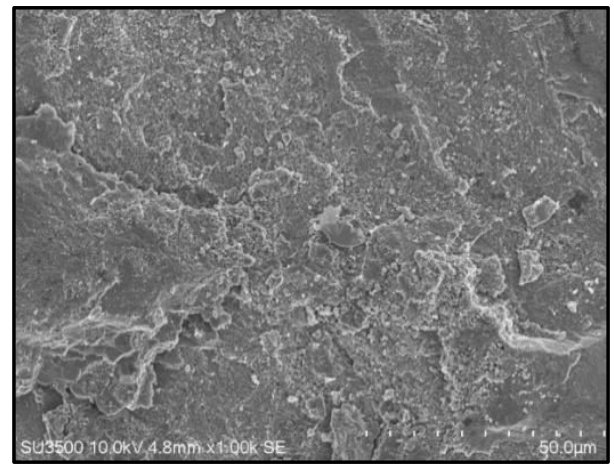

Fig. 10. SEM image, taken from the external surface of failure tube, showing the corrosion scale/deposited which are spreaded around

\subsection{Chemical Analysis}

The chemical composition of failure tube was analyzed by a spectrometer. The estimated chemical composition was listed in Table 2, and conform to the desired specification of A 106 grade B (plain carbon steel)

Table 2. The chemical composition of the failed tube

\begin{tabular}{|c|c|c|c|}
\hline \multirow{2}{*}{ Element } & \multicolumn{2}{|c|}{ Standard } & \multirow{2}{*}{ Lab. } \\
\cline { 2 - 4 } & MIN & MAX & \\
\hline Carbon (C) & & 0.300 & 0.164 \\
\hline Manganese (Mn) & 0.290 & $1.06^{*}$ & 0.653 \\
\hline Phosphorus (P) & & 0.035 & 0.015 \\
\hline Sulfur (S) & & 0.035 & 0.004 \\
\hline Silicon (Si) & 0.100 & & 0.213 \\
\hline Cooper (Cu) & & 0.400 & $<0.002^{* *}$ \\
\hline Nickel (Ni) & & 0.400 & $<0.005^{* *}$ \\
\hline Chrome (Cr) & & 0.400 & 0.014 \\
\hline Molybdenum (Mo) & & 0.150 & $<0.005^{* *}$ \\
\hline
\end{tabular}

\begin{tabular}{|c|c|c|c|} 
Vanadium $(\boldsymbol{V})$ & & 0.080 & $<0.002 * *$ \\
\hline $\boldsymbol{C r}+\boldsymbol{C u}+\mathbf{M o}+\mathbf{N i}+\boldsymbol{V}$ & & 1.0 & $<1.0$ \\
\hline
\end{tabular}

** value is under the quantification limit of equipment

The element analysis on the internal and external surface of the failure tube was also conducted using SEM-EDS. A typical EDS spectrum of the internal surface of the failure tube displays oxygen, natrium, sulphur, and calcium (Fig. 11).
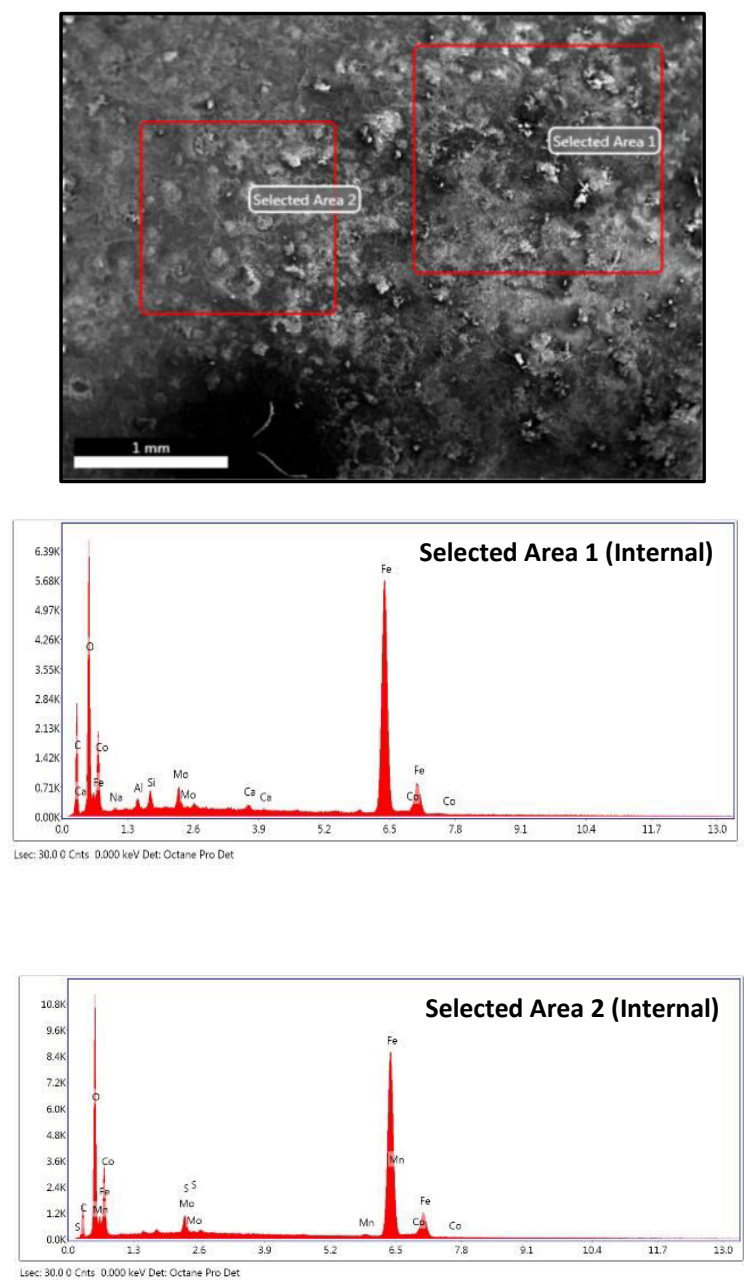

Fig. 11. A typical EDS spectrum of the internal surface of tube displays oxygen, natrium, sulphur, and calcium as forming elements of corrosion products and minerals

Table 3. The relative concentration of the element in internal location of selected area 1

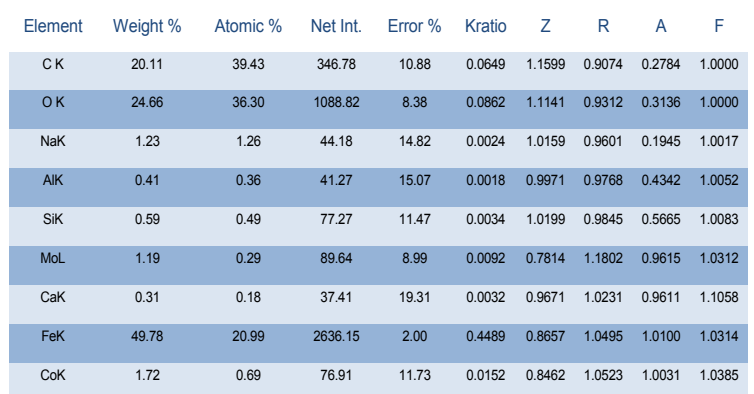


Table 4. The relative concentration of the element in internal location of selected area 2

\begin{tabular}{ccccccccc} 
Element & Weight \% & Atomic \% & Net Int. & Error \% & Kratio & $Z$ & $\mathrm{R}$ & $\mathrm{A}$ \\
\hline $\mathrm{CK}$ & 12.36 & 27.44 & 264.11 & 9.65 & 0.0385 & 1.1863 & 0.8943 & 0.2624 \\
\hline $\mathrm{OK}$ & 25.96 & 43.26 & 1819.31 & 7.59 & 0.1121 & 1.1401 & 0.9184 & 0.3786 \\
\hline MoL & 1.06 & 0.29 & 102.46 & 10.31 & 0.0082 & 0.8006 & 1.1674 & 0.9393 \\
\hline S K & 0.37 & 0.31 & 69.90 & 12.15 & 0.0030 & 1.0251 & 0.9877 & 0.7621 \\
\hline MnK & 0.47 & 0.23 & 42.68 & 17.20 & 0.0049 & 0.8738 & 1.0378 & 1.0059 \\
\hline FeK & 57.41 & 27.40 & 3995.31 & 1.91 & 0.5295 & 0.8882 & 1.0415 & 1.0083 \\
\hline CoK & 2.36 & 1.07 & 138.40 & 9.21 & 0.0212 & 0.8683 & 1.0446 & 0.9999
\end{tabular}

While external surface of the failure tube displays oxygen and sulphur (Fig. 12). Those results were confirmed as forming elements of corrosion products and minerals.
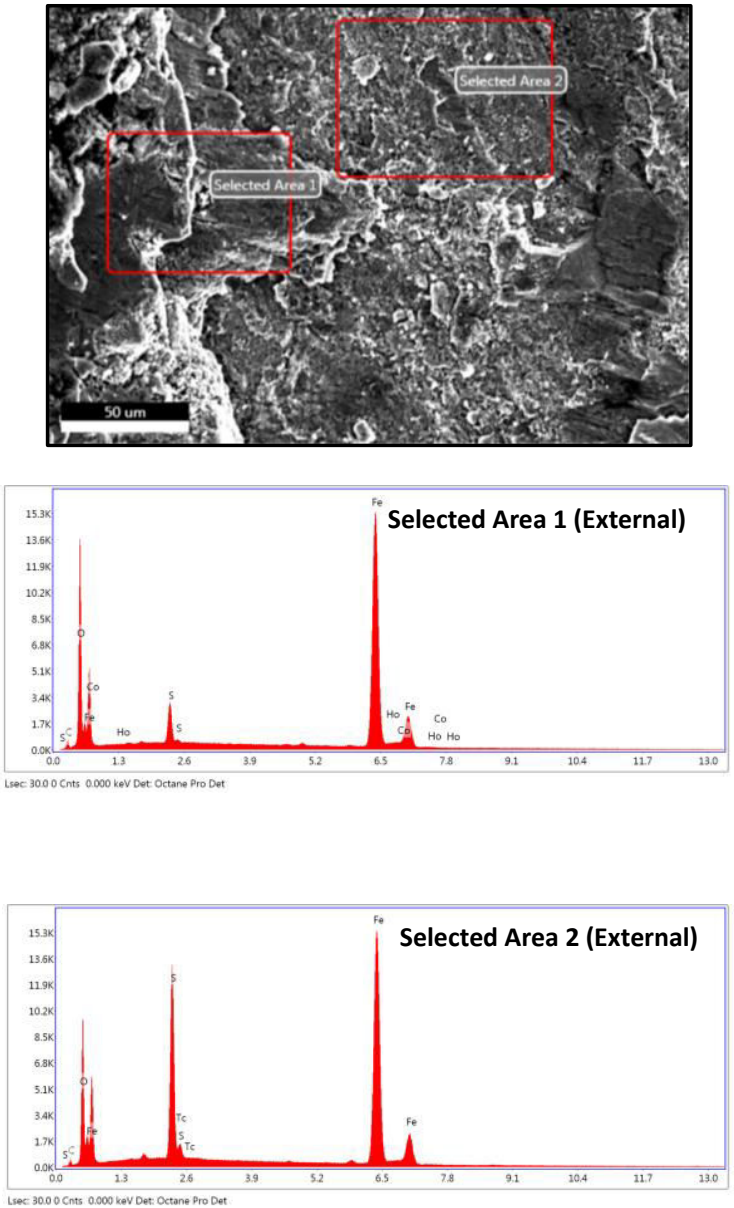

Fig. 12. A typical EDS spectrum of the external surface of tube displays oxygen and sulphur as forming elements of corrosion products and minerals

Table 5. The relative concentration of the element in external location of selected area 1

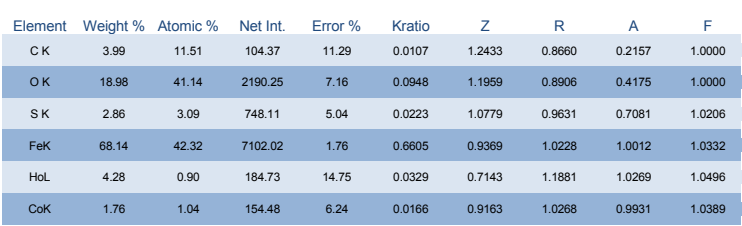

Table 6. The relative concentration of the element in external location of selected area 2

\begin{tabular}{cccccccccc} 
Element & Weight \% & Atomic \% & Net Int. & Error \% & Kratio & Z & R & A & F \\
\hline CK & 3.92 & 11.30 & 80.02 & 12.70 & 0.0078 & 1.2319 & 0.8727 & 0.1623 & 1.0000 \\
\hline OK & 15.48 & 33.53 & 1517.88 & 8.15 & 0.0627 & 1.1846 & 0.8972 & 0.3422 & 1.0000 \\
\hline SK & 12.10 & 13.08 & 3463.97 & 3.96 & 0.0986 & 1.0668 & 0.9691 & 0.7506 & 1.0176 \\
\hline TCL & 1.60 & 0.57 & 241.06 & 9.31 & 0.0128 & 0.8338 & 1.1505 & 0.9269 & 1.0305 \\
\hline FeK & 66.91 & 41.52 & 7152.32 & 1.75 & 0.6355 & 0.9261 & 1.0274 & 0.9976 & 1.0280 \\
\hline
\end{tabular}

An XRD analysis was subjected to internal and external corrosion product (scale/ deposit) and showed the presence of minerals such as sulphur. Sulphur mineral also found in the internal and external corrosion product, with the phase name of Pyrrhotite-3T, syn and Melanterite, respectively (Fig. 13 and Fig. 14).

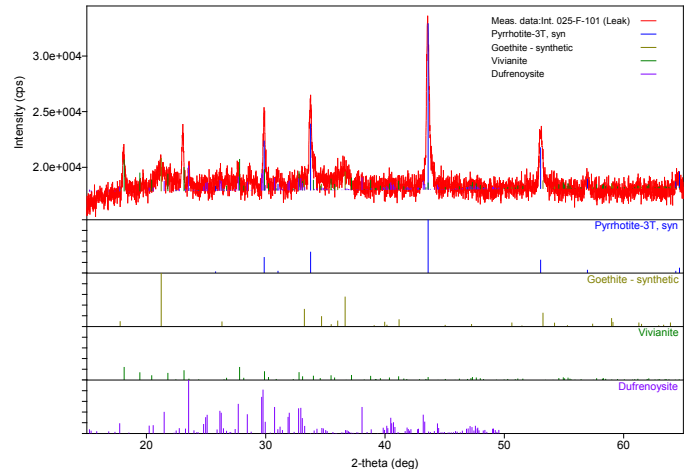

Fig. 13. A typical XRD spectrum of internal scale

Table 7. Compounds formula found on internal scale

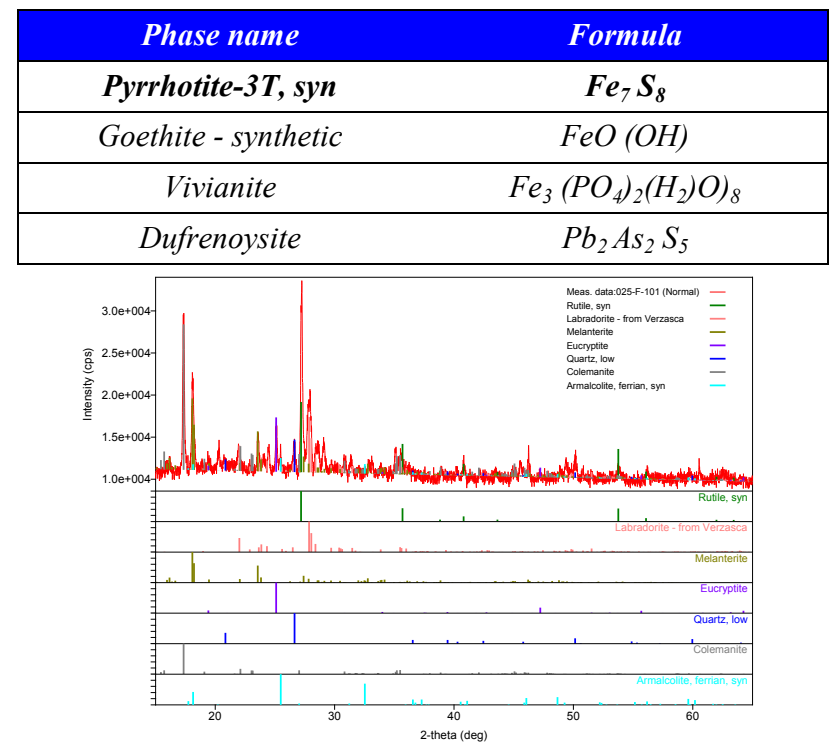

Fig. 14. A typical XRD spectrum of external scale

Table 8. Compounds formula found on external scale

\begin{tabular}{|cc|}
\hline Phase name & Formula \\
\hline Rutile, syn & $\mathrm{TiO}_{2}$ \\
\hline Labradorite - from Verzasca & $\mathrm{Ca}_{0.64} \mathrm{Na}_{0.35}\left(\mathrm{Al}_{1.63} \mathrm{Si}_{2.37} \mathrm{O}_{8}\right)$ \\
\hline Melanterite & $\mathrm{Fe} \mathrm{SO}_{4}\left(\mathrm{H}_{2} \mathrm{O}\right)_{7}$ \\
\hline Eucryptite & $\mathrm{Li} \mathrm{Al} \mathrm{Si} \mathrm{O}_{4}$ \\
\hline Quartz, low & $\mathrm{SiO}_{2}$ \\
\hline
\end{tabular}




\begin{tabular}{|cl|}
\hline Colemanite & $\mathrm{CaB}_{3} \mathrm{O}_{4}(\mathrm{OH})_{3} \mathrm{H}_{2} \mathrm{O}$ \\
\hline Armalcolite, ferrian, syn & $(\mathrm{MgFe})\left(\mathrm{Ti} \mathrm{i}_{3} \mathrm{Fe}\right) \mathrm{O}_{10}$ \\
\hline
\end{tabular}

\section{Discussion}

The result of analysis confirmed that the failure of heater hot oil tube was a leakage which is present at the inner side of the tube (Fig. 5), this leakage is caused by under deposit corrosion. The result of microstructure analysis, taken from the failed region, shows that the corrosion also occurs on the outer side of the tube, but not in dominantly (Fig. 8). Based on information obtained, the leaks of the tube take place in the bottom of the line between $5-7$ o'clock positions, close to the support/ hanger. According to the location, environment, and temperature of occurrence, this corrosion falls into categories which are localized, wet, and hightemperature corrosion, respectively.

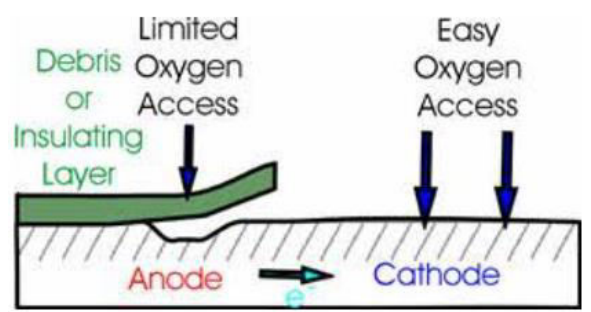

Fig. 15. Crevice corrosion mechanism

Under deposit corrosion is defined as localized corrosion that present on a steel surface, either underneath or around deposits [5], and accelerated corrosion can be found under solid deposits on the bottom of horizontal lines [6]. Under deposit corrosion has been more frequently cited as being responsible for different failures in the oil and gas industries over the past few years [7]. Severe corrosion problems such as crevice formation and pitting can be induced by solid deposits in pipelines because they provide a local environment which is chemically and physically different from the areas not covered by a deposit.

Deposition of solids helps prevent corrosive products from being removed by flow and limits corrosion inhibitors from accessing the metal surface. In the oil and gas industry, the deposit composition can be very complicated which leads to a very complex water chemistry underneath those deposits for corrosion analysis. $\mathrm{CO}_{2}, \mathrm{H}_{2} \mathrm{~S}, \mathrm{O}_{2}$, and often microbiological influenced corrosion mechanisms can be contributing to causing analyses of failures in the oil and gas industry [8].

The result of EDS analysis which is performed on the internal and external surface, also the result of XRD analysis which is performed on internal and external deposit indicates the formation of some mineral compounds. The result of EDS display elements which are oxygen, natrium, sulphur, and calcium (Fig. 11 and Fig. 12). In line with EDS result, XRD result displays several types of minerals compounds, two of them are Pyrrhotite-3T, syn and Melanterite, which is resulted from internal and external deposit products analysis, respectively (Fig. 13 and Fig. 14). This mineral contains iron sulphide in which when there is too much iron sulfide is formed, it no longer provides its protective service. It may crack and portions of it may flake off. The remaining deposits may provide the perfect environment for a crevice or under deposit corrosion.

Other than corrosion, the result of wall thickness measurement shows the erosion phenomena at the bottom of the tube (Table. 1). This is evidenced by comparing the result of wall thickness measurement at three different location of the tube (bottom side, top side, and right/left side).

\section{Corrosion rate of stee}

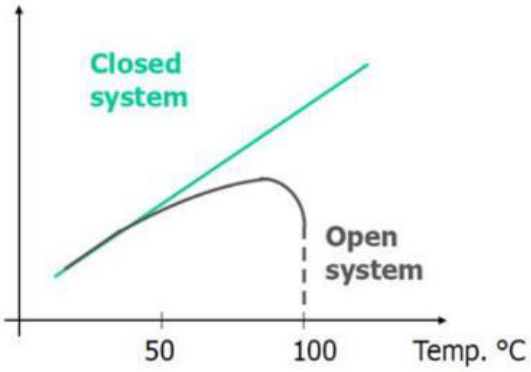

Fig. 16. The corrosion rate of steel vs temperature in the closed and open system

Answering the question about how the similar case of failure can happen for the second time, with the same failure mode, location, and also position of the failure, let's take a look at Fig. 8. When we observe the microstructures of the failed region at etched conditions and compare these microstructures with Fig. 7 (microstructures of the tube surface close to and far from the leakage), we found that there is spheroidization phenomena happened at the location of leakage (initial signs of carbide spheroidization). Spherodization can happen if there is local overheating at the location, this local overheating may come from the support/ hanger of the tube through conduction mechanism. So, the mechanisms of heat transfer happened at the failure point is conduction as well, not only radiation and convection mean that the location (pass 7, number 6, near the support/ hanger) will be a vulnerable location, in which local overheating can lead the acceleration of corrosion. The relation between corrosion rate vs temperature is drawn in Fig. 16.

\section{Conclusion and Recommendation}

Based on the results and discussion, it is concluded that heater hot oil tube is mainly failed due to under deposit corrosion which is present on the inner side of the tube. External corrosion/ fuel side corrosion also occurs, but not in dominantly. Local overheating was found at the location of the leakage which is caused by the additional transfer mechanism (conduction) comes from the support/ hanger.

As a recommendation, the plain carbon steel material in which the failure happened shall be replaced with 
A335 GP 9 (9Cr-1Mo), this material offer resistance to corrosion, good tensile strength, and resistance at hightemperature service. As prevention of local overheating, it is recommended to install a heat insulator between the support and the tube to reduce the effect of conduction.

\section{References}

1. Ş. Selcen KARAKOÇ. \& B.Dilhan CAM. Fired Heater Engineering Economics \& Design. Institute of Technology İzmir.

2. D. Ghosh. Failure Analysis of PRDS Pipe in a Thermal Power Plant Boiler. J. Inst. Eng. India Ser. C 99(2):233-238 (2018).

3. Metals Handbook, 9th Edition, Volume 11, Failure Analysis and Prevention (1986).

4. Charlie R. Brooks and Ashok Choudhury, Metallurgical Failure Analysis, McGraw Hill, Inc (1993).

5. Vera, J. R., Daniels, D. \& Achour, M. H. Under deposit corrosion (UDC) in the oil and gas industry: a review of mechanisms, testing and mitigation. Paper presented at the NACE Corrosion/12, paper no. 1379 (2012).

6. Espan, T., Kapusta, S. D. \& Simon Thomas, M. J. J. Case study: extreme corrosion of a 20" oil pipeline in the niger delta region. Paper presented at the NACE Corrosion/01, paper no. 629 (2001).

7. de Reus, J. A. Hendriksen, E. L. J. A., Wilms, M. E., Al-Habsi, Y. N., Durnie, W. H. \& Gough, M. A. Test methodologies and field verification of corrosion inhibitors to address under deposit corrosion in oil and gas production systems, Paper presented at the NACE Corrosion/05, paper no. 288 (2005).

8. API Standard 571, Damage Mechanism Affecting Fixed Equipment in Refinery Industry, Washington, DC. American Petroleum Institute (2003). 